\title{
First results from the GPS atmosphere sounding experiment TOR aboard the TerraSAR-X satellite
}

\author{
G. Beyerle $^{1}$, L. Grunwaldt ${ }^{1}$, S. Heise ${ }^{1}$, W. Köhler ${ }^{1}$, R. König ${ }^{1}$, G. Michalak ${ }^{1}$, M. Rothacher ${ }^{2}$, T. Schmidt ${ }^{1}$, J. Wickert ${ }^{1}$, \\ B. D. Tapley ${ }^{3}$, and B. Giesinger ${ }^{4}$ \\ ${ }^{1}$ GFZ German Research Centre for Geosciences, Potsdam, Germany \\ ${ }^{2}$ Swiss Federal Institute of Technology, Zurich, Switzerland \\ ${ }^{3}$ Center for Space Research, University of Texas (UT-CSR), Austin, TX, USA \\ ${ }^{4}$ Broad Reach Engineering, Tempe, AZ, USA
}

Received: 9 August 2010 - Published in Atmos. Chem. Phys. Discuss.: 24 November 2010

Revised: 29 April 2011 - Accepted: 14 June 2011 - Published: 13 July 2011

\begin{abstract}
GPS radio occultation events observed between 24 July and 17 November 2008 by the IGOR occultation receiver aboard the TerraSAR-X satellite are processed and analyzed. The comparison of 15327 refractivity profiles with collocated ECMWF data yield a mean bias between zero and $-0.30 \%$ at altitudes between 5 and $30 \mathrm{~km}$. Standard deviations decrease from about $1.4 \%$ at $5 \mathrm{~km}$ to about $0.6 \%$ at $10 \mathrm{~km}$ altitude, however, increase significantly in the upper stratosphere. At low latitudes mean biases and standard deviations are larger, in particular in the lower troposphere. The results are consistent with 15159 refractivity observations collected during the same time period by the BlackJack receiver aboard GRACE-A and processed by GFZ's operational processing system. The main difference between the two occultation instruments is the implementation of openloop signal tracking in the IGOR (TerraSAR-X) receiver which improves the tropospheric penetration depth in terms of ray height by about $2 \mathrm{~km}$ compared to the conventional closed-loop data acquired by BlackJack (GRACE-A).
\end{abstract}

\section{Introduction}

On 15 June 2007 the radar satellite TerraSAR-X $(4.9 \mathrm{~m}$ in height, $2.4 \mathrm{~m}$ in diameter, $1230 \mathrm{~kg}$ total mass and a payload mass of about $394 \mathrm{~kg}$ ) was launched with a Russian Dnepr1 rocket from Baikonur Cosmodrome, Kazakhstan and successfully injected into a sun-synchronous low-Earth orbit at an altitude of about $514 \mathrm{~km}$ and about $97.4^{\circ}$ inclination

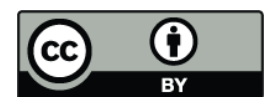

Correspondence to: G. Beyerle (gbeyerle@gfz-potsdam.de)
(Werninghaus and Buckreuss, 2010). Having successfully completed its commissioning phase TerraSAR-X reached operational status on 7 January 2008; its design life time is $5 \mathrm{yr}$.

TerraSAR-X's primary payload is a X-band synthetic aperture radar providing images of the Earth's surface with a maximum geometric resolution of about one meter (Pitz and Miller, 2010). In addition, the spacecraft is equipped with a laser communication instrument and the Tracking, Occultation and Ranging (TOR) experiment (Rothacher et al., 2007). TOR consists of a retroreflector array for satellite laser ranging measurements and the geodetic-grade Integrated GPS Occultation Receiver (IGOR). IGOR's dualfrequency carrier phase observations are used to derive the spacecraft's precise orbit with centimeter precision. Furthermore, IGOR performs GPS radio occultation (GPSRO) observations through dedicated antenna arrays mounted at the bow and stern of the spacecraft. In the following we describe the first analysis results obtained from IGOR's GPSRO measurements.

In GPSRO measurement mode signals transmitted by GPS satellites setting beyond or rising above the horizon are recorded with high sampling frequencies (Yunck et al., 2000; Kursinski et al., 1997). The signals' propagation through the ionosphere and neutral atmosphere causes characteristic changes in carrier phase and signal-to-noise ratio (SNR) which allow for the characterization of electron densities and sporadic E occurrences in the ionosphere (Hajj and Romans, 1998; Heise et al., 2002; Arras et al., 2008) and the derivation of refractivity and (dry) temperature profiles at altitudes below about 35 to $40 \mathrm{~km}$ (Kursinski et al., 1997). Figure 1 illustrates the GPSRO geometry schematically and defines the line-of-sight altitude (LSA). We note, that the base points

Published by Copernicus Publications on behalf of the European Geosciences Union. 


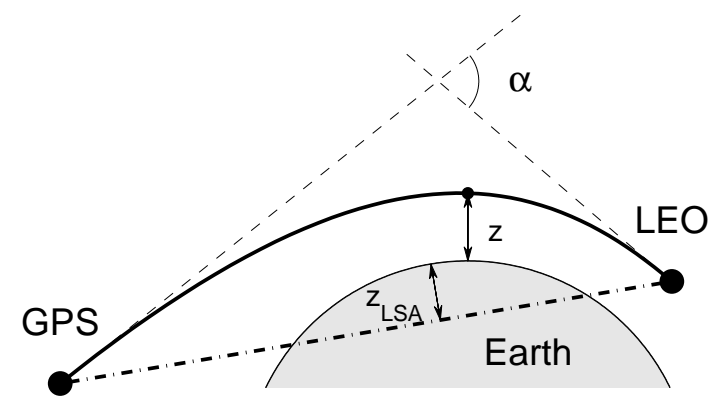

Fig. 1. Schematic diagram of the occultation geometry. Ionospheric and atmospheric refraction deflects the ray (solid line) by bending angle $\alpha . z$ denotes the altitude of the ray tangent point above the ellipsoid, $z_{\text {LSA }}$ the line-of-sight (dashed-dotted) altitude. Note that in the lower troposphere $z_{\text {LSA }}$ may become negative. (Figure is not to scale.)

(tangent point projected on Earth's surface) corresponding to LSA altitude $z_{\text {LSA }}$ and altitude $z$ in general deviate from each other.

Using the hydrostatic equation and the ideal gas law, vertical profiles of atmospheric refractivity are transformed into dry temperature and pressure profiles (Kursinski et al., 1997; Wickert et al., 2004). With auxiliary temperature data from meteorological analyses lower tropospheric humidity profiles are extracted from the GPSRO measurements as well (Gorbunov et al., 1996; Heise et al., 2006). GPSRO data is being used by a growing number of research groups worldwide and is considered a valuable data source for numerical weather predictions (see, e.g., Kuo et al., 2000; Anthes et al., 2008; Healy, 2008; Rennie, 2010), atmospheric physics research (see, e.g., Schmidt et al., 2008; Randel et al., 2003) and climate change studies (see, e.g., Ringer and Healy, 2008; Foelsche et al., 2008; Steiner et al., 2009; Schmidt et al., 2010).

Beginning with the proof-of-concept GPS/MET mission GPSRO instruments were placed on a number of spacecrafts, such as CHAMP, GRACE-A/GRACE-B, SAC-C, Ørsted, the six-satellite COSMIC constellation, MetOp-A and OCEANSAT-2 (see, e.g., Rocken et al., 1997; Wickert et al., 2009; Hajj et al., 2002; Anthes et al., 2008; Luntama et al., 2008; Perona et al., 2007; Schreiner et al., 2010). On 21 June 2010, TerraSAR-X was joined by TanDEM-X, which is equipped with an identical IGOR GPS receiver instrument.

The paper is sectioned as follows. After a brief description of the measurement instrument, the data reduction process from raw observation to excess phase profiles is described. The third section discusses the sensitivity of the derived refractivities on corrections applied to the excess phase processing and, furthermore, presents the first results from a 16 week measurement period in late summer/early fall of 2008.

\section{Instrument description}

IGOR is a commercial, space-qualified GPS receiver derived from the BlackJack receiver series designed by NASA's Jet Propulsion Laboratory (Pasadena/CA, USA). BlackJack receivers were and are still being operated successfully on a number of low-Earth orbiting spacecrafts. Whilst IGOR's design is mainly unchanged from its predecessor, the main difference between IGOR and BlackJack is the former's larger percentage of space-qualified electronic components. The IGOR receiver hardware is manufactured by Broad Reach Engineering Inc. (Tempe/AZ, USA); Center for Space Research at the University of Texas (UT-CSR) provided mission-specific firmware versions. The instrument implemented aboard TerraSAR-X is a modified version of the receiver hardware developed for the COSMIC constellation (Anthes et al., 2008; Schreiner et al., 2010).

The IGOR receiver design is based on the PowerPC 603e CPU and supports a total of four dual-frequency L-band antennas, two for Precise Orbit Determination (POD) and two for occultation measurements. Internally, the receiver consists of two independent digital boards which can be connected to all four RF antenna sections. IGOR's 48 tracking channels are grouped into sets of three, tracking GPS signals modulated with $\mathrm{C} / \mathrm{A}(\mathrm{L} 1), \mathrm{P}(\mathrm{L} 1)$ and $\mathrm{P}(\mathrm{L} 2)$ codes. Thus, the receiver can track up to 16 GPS satellites independently. A maximum of 36 channels (three signal modulations from 12 satellites) are assigned to POD and up to 12 channels (three signal modulations from 4 satellites) are available to occultation measurements. The receiver firmware is implemented in a modular way, individual components may be modified during the mission by firmware uploads.

During each occultation event IGOR aboard TerraSAR$\mathrm{X}$ tracks a reference signal, selected from those GPS satellites appearing at high elevation angles, simultaneously with the signal from the occulting satellite. The reference signal is used to correct for the effects of receiver clock errors. Both signals, the occulting as well as the reference signal, are recorded at a sampling rate of about $50 \mathrm{~Hz}$; for technical reasons, however, the precise measurement epochs of the occulting and reference signal samples may deviate by up to $10 \mathrm{~ms}$ (see discussion below).

On the other hand, the IGOR instrument and its firmware differs from BlackJack deployed aboard CHAMP and GRACE-A/GRACE-B in several respects. First, on TerraSAR-X occultation signals are recorded by phasedarray GPS antennas which offer a higher gain in the azimuthal plane compared to the helix-type antennas used aboard CHAMP (see section 4.1). As a consequence the occultation antennas' field of view is vertically restricted and the reference signal (arriving at elevation angles between about $20^{\circ}$ and $90^{\circ}$ ) is recorded solely with the zenith antenna mounted on top of the spacecraft. Second, due to the enhanced X-band noise levels during SAR operations the general IGOR radio frequency design had to be modified for the 
TerraSAR-X mission. Narrow-band filter and preamplifier units were developed in order to efficiently suppress the Xband signals. These filter units are mounted on top of the receiver housing and close to the occultation antennas, respectively. Third, the IGOR instrument is driven by a temperature stabilized quartz clock which is adjusted at regular intervals to keep the GPS receiver clock time error below $1 \mu$ s with respect to GPS coordinate time. Unlike the BlackJack (CHAMP) instrument, however, the IGOR firmware suppresses these receiver clock adjustments during occultation events. Finally, the firmware currently loaded on the IGOR receiver supports open-loop C/A code signal tracking at low ray tangent point altitudes to counteract the premature loss of signal lock in the lower troposphere (see, e.g., Sokolovskiy, 2001; Sokolovskiy et al., 2006, 2007; Ao et al., 2009).

\section{Measurements and data analysis}

First GPSRO measurements with IGOR (TerraSAR-X) were conducted during three brief intervals in 2007 (on 27 June, on 27 July and from 19 to 23 November 2007). A longer campaign, lasting for 32 days, was performed between 15 January and 15 February 2008. Starting on 24 July 2008 occultation events were recorded on a continuous basis until 17 November 2008. In mid-February 2009 the IGOR receiver firmware was updated and occultation measurement mode was re-started on 17 February 2009. The following analysis and discussion focuses on observations recorded on 149 days between 24 July and 17 November 2008. With the exception of one week time period in early April 2010 only setting occultation events have been observed by IGOR (TerraSAR-X).

In a setting occultation event IGOR acquires dual frequency GPS data at an LSA of about $120 \mathrm{~km}$ and monitors the data in standard closed-loop (CL) tracking mode; at about $-15 \mathrm{~km}$ LSA the C/A code channel transitions to openloop (OL) tracking mode to avoid premature signal tracking loss in the lower troposphere (Sokolovskiy, 2001; Ao et al., 2009). OL tracking was implemented and is being successfully used by IGOR receivers aboard the COSMIC satellites (Anthes et al., 2008; Schreiner et al., 2010) as well as by the GRAS receiver aboard MetOp-A (in GRAS parlance termed 'raw sampling' tracking) (von Engeln et al., 2009). We note that IGOR's P code tracking of the L2 signal is restricted to CL operation; once the receiver transitions to OL mode, L2 carrier phase data are no longer available. Data recording of the IGOR (TerraSAR-X) ends at LSAs between -90 and $-150 \mathrm{~km}$, typically. A histogram distribution of start, transition and end altitudes is shown in Fig. 2.

GPSRO observations are analyzed in three consecutive steps. First, IGOR raw data packets are extracted from the GPS data stream and individual occultation events are identified. The corresponding time-tagged carrier phase and SNR

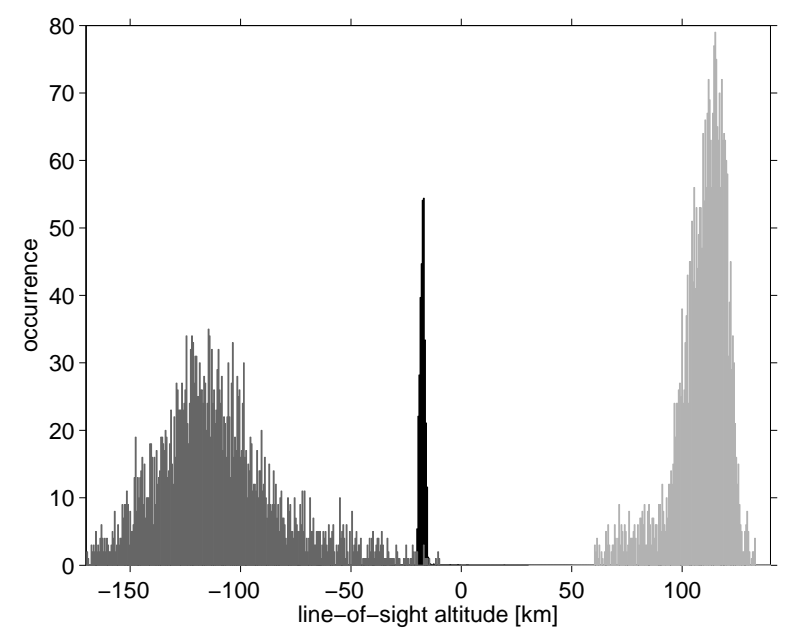

Fig. 2. Histogram distribution of line-of-sight altitudes marking the start (light grey) and end (dark grey) of occultation events; the altitudes of the transition between closed-loop and open-loop tracking is marked in black. The analysis is based on 3182 setting GPSRO events recorded between 7 and 21 August 2008. For clarity, the occurrence of the CL/OL transition heights is reduced by a factor of ten.

data from the occulting and the referencing satellite acquired during each occultation event (lasting for about 100 to $150 \mathrm{~s}$, typically) are collected and stored in separate data files. In the next processing step carrier phase changes caused by clock drifts and the relative motion between transmitter and receiver are determined using POD information on the GPS and the TerraSAR-X spacecrafts. The POD data files, which are provided operationally by GFZ's precise orbit determination group (König et al., 2005; Michalak and König, 2010a,b), contain these estimates of positions, velocities and clock errors with a temporal resolution of $30 \mathrm{~s}$. The POD data are interpolated on the occultation measurement epochs and the corresponding carrier phase contributions are calculated. In addition, the phase data are corrected for relativistic and time-of-flight effects, antenna phase center offsets and carrier phase wind-up (Kursinski et al., 1997; Hajj et al., 2002; Wickert et al., 2009; Wu et al., 1993; Beyerle, 2009) and a single differencing scheme is employed to extract excess phase path profiles (Wickert et al., 2002).

Finally, the excess phase paths are transformed into vertical profiles of bending angle and Abel-inverted to atmospheric refractivity. The processing steps from excess phase paths to bending angle, refractivity and dry temperature profiles are described by Kursinski et al. (1997); Wickert et al. (2004); Gorbunov and Lauritsen (2004); Jensen et al. (2004); the processing algorithms leading from raw data to excess phase path profiles have been discussed by Hajj et al. (2002). TerraSAR-X GPSRO results, described and discussed in the following, are derived with GFZ's experimental GPSRO processing system POCS-X. 


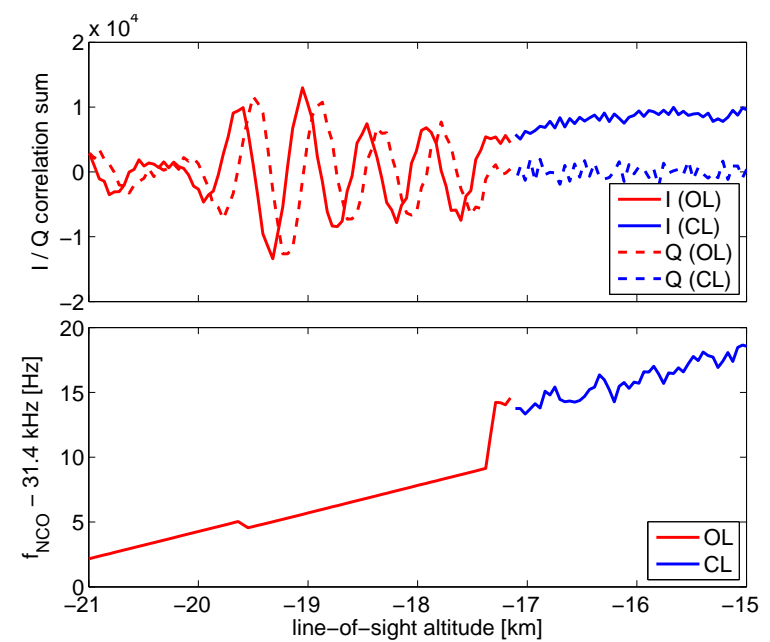

Fig. 3. Transition between closed-loop (line-of-sight altitude above $-17.2 \mathrm{~km}$ ) and open-loop mode (line-of-sight altitude below $-17.2 \mathrm{~km}$ ). Top: in-phase (solid line) and quadrature-phase (dashed line) correlation sum samples as a function of line-of-sight altitude. Samples acquired in closed-loop (open-loop) mode are plotted in blue (red). Bottom: the corresponding NCO frequency (for clarity shifted by $31.4 \mathrm{kHz}$ ) as a function of line-of-sight altitude. For details see text.

Unlike the BlackJack (CHAMP, GRACE-A/GRACEB) receivers, IGOR (TerraSAR-X) outputs in-phase (quadrature-phase) correlation sum samples $\tilde{I}_{n} \equiv I_{n} / D_{n}$ ( $\tilde{Q}_{n} \equiv Q_{n} / D_{n}$ ) of the occulting signal. (The reference link data packets lack the correlation sum samples.) Here, $D_{n}= \pm 1$ denotes the navigation data bit (see below) and $I_{n}$ $\left(Q_{n}\right)$ the demodulated in-phase (quadrature-phase) correlation sum for sample number $n$. In closed-loop tracking mode total carrier phase samples $\varphi_{n}$ are transmitted by IGOR; in open-loop mode, however, the receiver sends numericallycontrolled oscillator (NCO) phase samples $\varphi_{n}^{\mathrm{NCO}}$ instead of $\varphi_{n}$ and the total carrier phase $\varphi_{n}$ needs to be reconstructed from $\varphi_{n}^{\mathrm{NCO}}$ and the residual phase samples $\varphi_{n}^{\text {res }}$

$\varphi_{n}=\varphi_{n}^{\mathrm{NCO}}+\varphi_{n}^{\mathrm{res}}$

where

$\varphi_{n}^{\text {res }}=\operatorname{atan} 2\left(Q_{n}, I_{n}\right)+C_{n}$.

The phase unwrapping term $C_{n}$ is calculated from

$C_{n}=\left\{\begin{array}{cll}C_{n-1}+2 \pi & : & \operatorname{atan} 2\left(Q_{n}, I_{n}\right)-\operatorname{atan} 2\left(Q_{n-1}, I_{n-1}\right)<-\pi \\ C_{n-1}-2 \pi & : & \operatorname{atan} 2\left(Q_{n}, I_{n}\right)-\operatorname{atan} 2\left(Q_{n-1}, I_{n-1}\right)>+\pi \\ C_{n-1} & : & \text { else }\end{array}\right.$

with $C_{1}=0$ and atan 2 denoting the four-quadrant inverse tangent (Beyerle et al., 2006). Eq. 3 corrects a sign error in equation (16) of Beyerle et al. (2006).

The transition between CL and OL tracking mode in terms of (demodulated) in-phase and quadrature-phase correlation sums is illustrated in Fig. 3. It shows $I_{n}$ and $Q_{n}$ samples as a function of LSA (top panel). Occultation event number 0502 (occulting satellite PRN 24) starts on 7 August 2008, $5 \mathrm{~h}: 02 \mathrm{~min}$ (GPS time) at an LSA of $+104.9 \mathrm{~km}$ and ends at an LSA of $-105.6 \mathrm{~km}$; at about $-17.2 \mathrm{~km} \mathrm{LSA}$ the receiver switches from CL to OL tracking.

Since the true atmospheric state is unknown a priori, the OL Doppler model differs from the true Doppler by a few $\mathrm{Hz}$ and the correlation sums $I$ and $Q$ start to oscillate, once OL mode is active (Ao et al., 2009). The bottom panel in Fig. 3 shows the derivative of NCO phase $\varphi_{n}^{\mathrm{NCO}}$ with respect to time (i.e. NCO frequency) as a function of LSA. (Since in $\mathrm{CL}$ tracking mode the IGOR output lacks information on the NCO carrier phases, the $\mathrm{CL} \varphi_{n}^{\mathrm{NCO}}$ samples are estimated from the CL $\varphi_{n}^{\text {res }}$ using Eqs. 1 and 2.) The noise of $\varphi_{n}^{\mathrm{NCO}}$ in CL mode is determined by the bandwidth of carrier tracking loop (see, e.g., Misra and Enge, 2006). Once IGOR switches to OL mode, the carrier NCO is controlled by the Doppler model and the phase noise disappears. The step-like feature at $-19.5 \mathrm{~km}$ LSA is caused by an adjustment of the Doppler model. These adjustments occur at integer seconds receiver time since the onboard navigation solution (which affect the OL Doppler frequency shifts) is updated once per second (for details see Ao et al., 2009). We note that during one second the (upper tropospheric or stratospheric) altitude changes by about $2 \mathrm{~km}$.

Information on the tracking state is transmitted by IGOR as part of high-rate $(50 \mathrm{~Hz})$ raw data packets, which comprise phase and amplitude samples collected during $1 \mathrm{~s}$ (receiver time). I.e. the tracking state's temporal resolution is about $1 \mathrm{~Hz}$ and each packet contains between 49 and 51 samples. The tracking state corresponding to each individual measurement sample, however, is not encoded in the raw data stream. The following analysis is based on the assumption that tracking state transitions are aligned to the raw data packet boundaries. The switch from the CL to the OL tracking state is indicated in Fig. 3 by a color change from blue to red. Inspection of the top and bottom panel in Fig. 3 suggests, that the assumption regarding the alignment of OL-to-CL tracking state transitions might not strictly be true. It appears that the data packet starting at about $-17.2 \mathrm{~km}$ LSA (and ending at about $-19.6 \mathrm{~km} \mathrm{LSA}$ ) contains about 4 CL samples before the switch to OL mode occurs at about $-17.4 \mathrm{~km} \mathrm{LSA.}$

Eq. 2 requires knowledge of the navigation data bits $D_{n}$ of the occulting satellite at the time of observation. For this purpose GFZ established a network of ground-based GPS receivers to monitor the navigation data bit stream (Beyerle et al., 2009). During the time period considered here, six out of 27 receivers within GFZ's groundstation network provided a data stream of $D_{n}$ producing a global coverage of about $95 \%$. I.e. on average about $5 \%$ of the occultation events could not be processed due to missing $D_{n}$. "Internal" navigation bit determination (Sokolovskiy et al., 2009) is not used by the POCS-X GPSRO processing system. 
TerraSAR-X phase path profiles are calculated using single differencing to correct for receiver clock errors (Wickert et al., 2002; Hajj et al., 2002). Two alternative methods, zero differencing and single differencing with reduced reference link sampling rate ("reduced single differencing"), are investigated as well (see following section).

As noted above, IGOR (TerraSAR-X) outputs the occultation link's carrier phase data in terms of two separate quantities, the NCO carrier phase and the in-phase/quadraturephase correlation sum samples not only in the OL, but also in the CL tracking state. In the latter case the "internal" navigation bits may be extracted from the in-phase correlation samples using $\tilde{D}_{n} \equiv s \quad I_{n} /\left|I_{n}\right|$ with an over-all sign factor $s=+1$ or $s=-1$. $(|x|$ denotes the modulus of $x$.) Since the observed ("external") navigation bits $D_{n}$ should agree with the "internal" $\tilde{D}_{n}$, provided sufficient SNR is available for the carrier phase-locked loop to track the signal without (half-)cycle slips, any differences between $\tilde{D}_{n}$ and $D_{n}$ can be utilized to validate the proper performance of the carrier tracking loop in CL mode. In fact, an analysis of $20833 \mathrm{ob}-$ servations exhibits differences in 7235 cases $(34.7 \%)$, in 3580 cases $(17.2 \%)$ more than 50 occurrences of deviating navigation data bits are found. Inspection shows that these bit deviations occur predominantly if (C/A code) SNR values are below 50 to $100 \mathrm{~V} / \mathrm{V}$ or if these SNR values exhibit strong fluctuations.

First GPSRO measurements with IGOR (TerraSAR-X) were conducted during three brief intervals in 2007 (on 27 June, on 27 July and from 19 to 23 November 2007). A longer campaign, lasting for 32 days, was performed between 15 January and 15 February 2008. Starting on 24 July 2008 occultation events were recorded on a continuous basis until 17 November 2008. In mid-February 2009 the IGOR receiver firmware was updated and occultation measurement mode was re-started on 17 February 2009. The following analysis and discussion focuses on observations recorded on 149 days between 24 July and 17 November 2008. With the exception of a one week time period in early April 2010 only setting occultation events have been observed by IGOR (TerraSAR-X).

\section{Discussion}

This section addresses three topics: first, the TerraSAR-X occultation antenna's gain pattern is compared to the helix antenna's pattern used onboard CHAMP and GRACEA/GRACE-B; second, alternatives to the standard single differencing method are investigated; third, the TerraSAR-X GPSRO refractivity observations are validated with collocated European Centre for Medium-Range Weather Forecasts (ECMWF) data and compared to GRACE-A observations recorded during the same time period.

The study is based on the analysis of setting occultation events recorded between 24 July 2008 and 17 November
Table 1. Occultation events statistics for 39987 raw observations recorded between 24 July and 17 November 2008. 39987 $-20833=19154$ events are removed in the first processing stage (derivation of excess phase paths from IGOR raw data), another $20833-15327=5506$ events are flagged as deficient in the second processing stage (derivation of bending angle and refractivity profiles from excess phase profiles).

\begin{tabular}{lrl}
\hline & occurrences & description \\
\hline & 39987 & number of raw data observations \\
- & 11437 & occultation event too short \\
- & 2396 & missing navigation bit data \\
- & 1423 & precise orbit information lacking \\
- & 3898 & other errors \\
\hline & 20833 & number of remaining excess phase profiles \\
- & 4165 & ionospheric correction failed \\
- & 827 & insufficient altitude range \\
- & 514 & other errors \\
\hline & 15327 & number of remaining refractivity profiles \\
\hline
\end{tabular}

2008. Starting from a data set of 20833 excess phase path profiles recorded between 24 July 2008 and 17 November 2008 a total of 15327 refractivity profiles are derived. Table 1 provides information on the statistics of the first and second processing stage.

\subsection{Antenna gain pattern}

To the best of our knowledge, laboratory calibration data of the TOR occultation antenna array's gain functions are not available. Nevertheless the gain pattern's qualitative shape can still be determined from the observed signal strengths. Figure 4 shows the C/A code SNR values at about $40 \mathrm{~km}$ LSA as a function of azimuth angle derived from IGOR (TerraSAR-X) and BlackJack (CHAMP) observations within the same 21 day time period of 7 to 27 August 2008. In addition, the theoretically expected gain function, adjusted to the IGOR data by linear regression, is shown as well (green line).

The comparison of the IGOR SNR values (marked in red) with the CHAMP data (marked in blue) illustrate the improved gain pattern of the TerraSAR-X antenna array in particular at azimuth angles larger than $+20^{\circ}$ and smaller than $-20^{\circ}$. As a consequence of the array design the TOR occultation antenna exhibits a narrower field of view in the vertical direction (not shown) and, thus, the reference link data cannot be recorded through the occultation antenna, but has to be observed via the zenith-oriented antenna. For comparison, in about $70 \%$ of CHAMP occultation events the reference signal is observed with the occultation (helix) antenna which has similar gain patterns in the vertical and horizontal (azimuthal) direction. The data in Fig. 4 indicate a slight left-right asymmetry of IGOR's antenna gain pattern which 


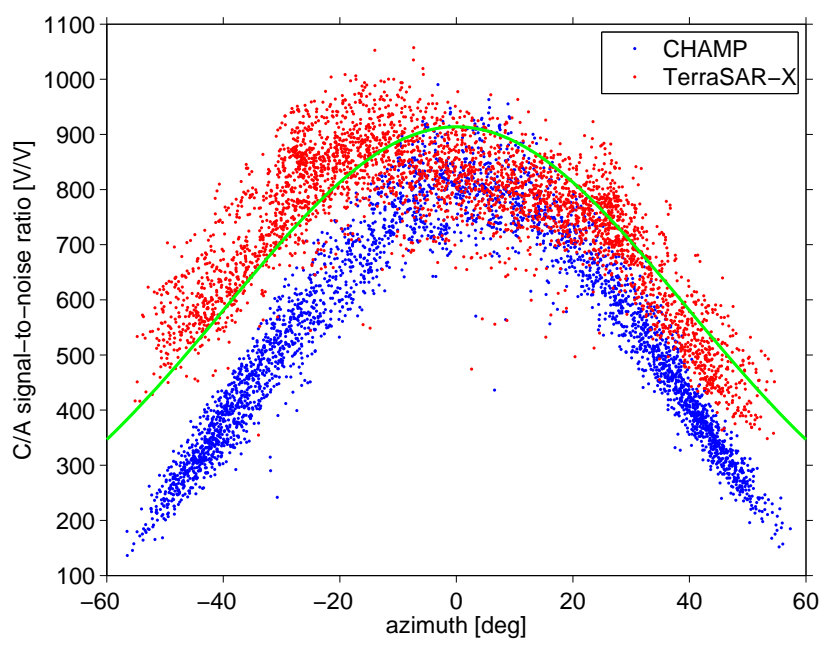

Fig. 4. C/A code SNR values at a line-of-sight altitude of $40 \mathrm{~km}$ versus the azimuth angle of the corresponding observation. The figure shows 3182 occultation events recorded by IGOR (TerraSAR$\mathrm{X}$ ) between 7 and 27 August 2008 marked in red. For comparison 3034 events recorded by BlackJack (CHAMP) during the same time period are shown (blue dots). The green line is derived from the theoretically expected occultation antenna's gain function.

most likely is related to the antenna's off-axis mounting position aboard TerraSAR-X.

\subsection{Single versus zero differencing}

As mentioned above (see section 2), in GPSRO measurement mode IGOR tracks a reference signal from a suitably selected GPS satellite at about $50 \mathrm{~Hz}$ sampling rate in parallel to the occulting satellite's signal. In a single differencing retrieval the reference signal is used to eliminate excess phase deviations caused by the receiver clock errors (Wickert et al., 2002). Single differencing, however, comes at the price of a significant increase in transmitted raw data volume compared to observations without reference link data. (The increase is about $60 \%$ and less than a factor of two, because the reference link data usually include C/A and P2 carrier phases only, SNR data are not recorded.)

Since the IGOR (TerraSAR-X) firmware features suppression of receiver clock adjustments during GPSRO measurement mode (see section 2), the question arises whether the present data set could be analyzed in zero differencing mode as well. To this end the IGOR (TerraSAR-X) observations recorded between 27 July and 17 November 2008 are processed without utilization of the reference link observations. Instead, IGOR's receiver clock biases are estimated by linear interpolation of the $30 \mathrm{~s}$ POD solutions. The comparison of the zero differencing results in terms of the fractional refractivity error $\Delta N^{\mathrm{ZD}}(z) / N^{\mathrm{E}}(z)$ with

$$
\Delta N^{X}(z) \equiv N^{X}(z)-N^{\mathrm{E}}(z)
$$
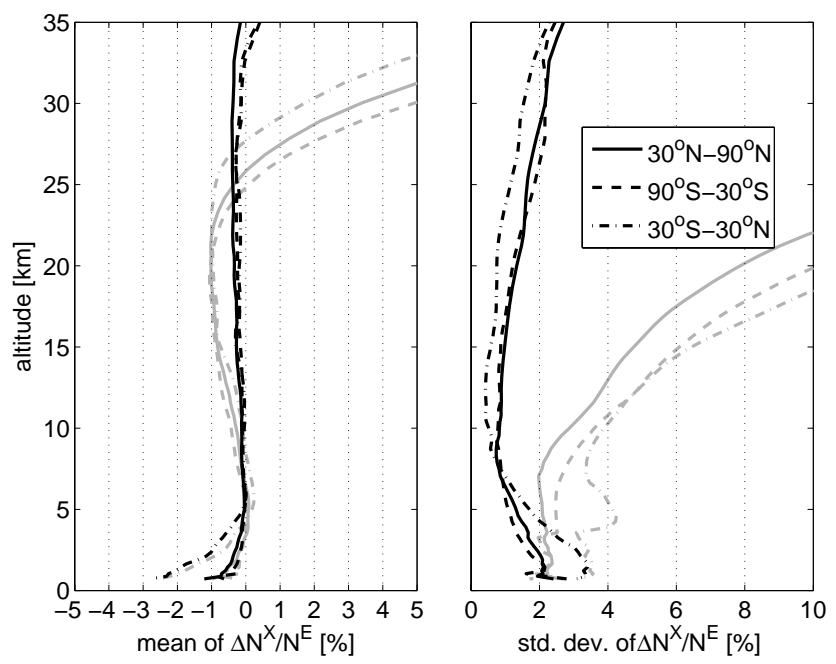

Fig. 5. Reduced rate differencing and zero differencing. Left: mean fractional refractivity error for three meridional zones; dashed line: $90^{\circ} \mathrm{S}-30^{\circ} \mathrm{S}$, dashed-dotted: $30^{\circ} \mathrm{S}-30^{\circ} \mathrm{N}$, solid: $30^{\circ} \mathrm{N}-90^{\circ} \mathrm{N}$. The sampling frequency on the reference link is reduced to $1 \mathrm{~Hz}$ (black lines); the corresponding zero differencing results are drawn as grey lines. Right: standard deviation of fractional refractivity error for $1 \mathrm{~Hz}$ single differencing (black) and zero differencing (grey).

where $X=\mathrm{ZD}$ (zero differencing), SD (single differencing), RRSD (reduced rate single differencing) or NCO. $N^{\text {ZD }}$ denotes the zero differencing refractivity and the mean and standard deviation of its fractional deviation from $N^{\mathrm{E}}(z)$ is plotted in Fig. 5 as grey lines. $N^{\mathrm{E}}(z)$ is the corresponding refractivity value extracted from the ECMWF meteorological field; the procedure is described in section 4.4.

Another option for lowering the raw data transmission bandwidth is sampling rate reduction on the reference link. We simulate this approach (in the following denoted as reduced rate single differencing) by downsampling the reference link C/A and P2 data from $50 \mathrm{~Hz}$ to $1 \mathrm{~Hz}$. Next, the $1 \mathrm{~Hz}$ data are upsampled again by linear interpolation and processed using the single differencing algorithm. The results are included in Fig. 5 as well; the comparison between derived refractivities and corresponding ECMWF analysis data in terms of the mean and standard deviation of the fraction refractivity error are plotted as black lines.

The comparison between ZD and RRSD results in Fig. 5 exhibits significant biases and enhanced standard deviations of $\Delta N^{\mathrm{ZD}}(z) / N^{\mathrm{E}}(z)$ starting already in the lower troposphere in comparison to the corresponding RRSD results derived from $\Delta N^{\mathrm{RRSD}}(z) / N^{\mathrm{E}}(z)$. The good agreement between the RRSD results (black lines in Fig. 5) and the SD results (Fig. 11 below) suggests that GPSRO raw data bandwidth could be reduced by about $60 \%$ by sampling the reference link at $1 \mathrm{~Hz}$ without significant loss of accuracy and precision. Second, the ZD results shown here refute the assertion by Beyerle et al. (2005) who suggested that without internal 


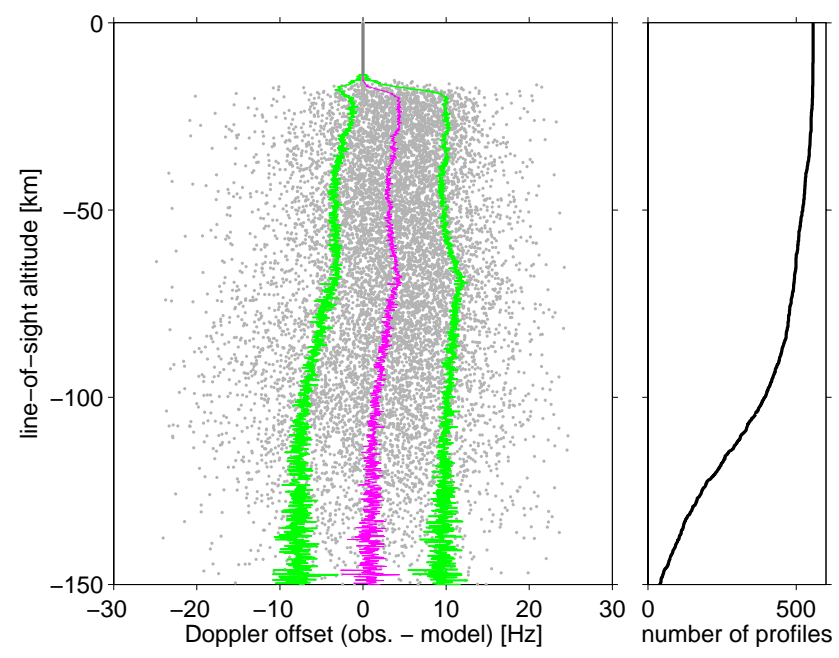

Fig. 6. Left: Difference between total and NCO frequency as a function of line-of-sight altitude. The mean and standard deviation are plotted in pink and green, respectively; the individual data points (for clarity only $2 \%$ of the data points are shown) are marked in grey. Right: number of observation samples as a function of lineof-sight altitude. For details see text.

clock adjustments zero differencing processing results of observations recorded by receivers without ultra stable oscillator support were comparable to single differencing results. Rather, with presently available 30 s POD solutions zero differencing requires the presence of an ultra stable oscillator clock driving the GPSRO receiver.

\subsection{Open-loop tracking}

As noted above, IGOR transitions to OL tracking mode at an LSA of about $-15 \mathrm{~km}$ (see Fig. 2). As a consequence the carrier NCO's Doppler frequency

$f^{\mathrm{NCO}}=\frac{d \varphi^{\mathrm{NCO}}}{d \hat{t}}$

deviates from the true Doppler frequency

$f=\frac{d \varphi}{d \hat{t}}$.

once the receiver transitions to OL mode (Sokolovskiy, 2001; Beyerle et al., 2006; Ao et al., 2009). Here, the time derivative is performed with respect to receiver time $\hat{t}$. Figure 6 illustrates this offset between OL Doppler (NCO frequency) and true Doppler frequency, where we assume that the observed Doppler frequency may be regarded as the true Doppler frequency. In the following, the time series of $f^{\mathrm{NCO}}$ samples is denoted as OL Doppler model.

The left panel of Fig. 6 shows the difference $f-f^{\mathrm{NCO}}$ as a function of LSA (grey dots) observed in 557 occultation events between 7 and 9 August 2008. The mean value of $f-f^{\mathrm{NCO}}$, averaged at each LSA level, is marked in pink; green lines delineate the standard deviation. The right panel indicates the number of observation samples. The profile of the mean Doppler difference agrees with the difference profile determined by Ao et al. (2009) from SAC-C observations. (Inspection of Fig. 5a in Ao et al. (2009), however, suggests that OL tracking in BlackJack (SAC-C) is activated about $15 \mathrm{~km}$ (LSA) higher than in IGOR (TerraSAR-X).)

An OL sampling frequency of $50 \mathrm{~Hz}$ implies that the values of $f-f^{\mathrm{NCO}}$ are restricted to the frequency interval $[-25 \mathrm{~Hz},+25 \mathrm{~Hz}]$; frequencies exceeding this range are aliased back into the interval $[-25 \mathrm{~Hz},+25 \mathrm{~Hz}]$ and distort the OL measurement. The standard deviations are about $10 \mathrm{~Hz}$, well below the $15 \mathrm{~Hz}$ limit estimated by (Sokolovskiy, 2001). On the other hand, assuming the frequency samples follow a Gaussian distribution, $37 \%$ of all samples exceed the 1- $\sigma$ level. Only at the 3- $\sigma$ level (corresponding to about $30 \mathrm{~Hz}$ ) this fraction decreases to $5 \%$. Thus, an OL sampling frequency of at least $80 \mathrm{~Hz}$ (twice the sum of $10 \mathrm{~Hz}$ maximum Doppler frequency bias and a 3- $\sigma$ deviation of $30 \mathrm{~Hz}$ ) is necessary to track $95 \%$ of the occultation events without aliasing effects. Future firmware implementations should allow for a sampling frequency increase to at least $80 \mathrm{~Hz}$. These findings are consistent with recent results from the MetOp-A GRAS GPSRO instrument (Bonnedal et al., 2010; von Engeln et al., 2009).

The BlackJack (SAC-C) receiver and the IGOR (COSMIC) receivers modify not only the carrier loop's but also the code loop's tracking algorithm if the tracking mode transitions from CL to OL. In a rising occultation event the instrument starts out in OL tracking mode and the code $\mathrm{NCO}$ is controlled by a range model taking into account the estimated position and clock errors of the signal transmitter and receiver. In a setting event the range offsets are obtained directly from the carrier NCO output (Ao et al., 2009). Since the IGOR (TerraSAR-X) firmware is based on the IGOR (COSMIC) implementation it is assumed that TOR utilizes the same signal tracking strategy.

This assumption is confirmed by an analysis of the excess range

$E_{n}^{\mathrm{NCO}} \equiv \rho_{n}^{\mathrm{C} / \mathrm{A}}-\frac{\lambda}{2 \pi} \varphi_{n}^{\mathrm{C} / \mathrm{A}, \mathrm{NCO}}+C^{\mathrm{NCO}}$

which is plotted in the left panel of Fig. 7. Here, $\rho_{n}^{\mathrm{C} / \mathrm{A}}$ denotes the (C/A code) pseudorange of sample $n, \varphi_{n}^{\mathrm{C} / \mathrm{A}, \mathrm{NCO}}$ the (C/A) NCO carrier phase and $\lambda$ the (L1) carrier wavelength; the offset $C^{\mathrm{NCO}}=-\left(\rho_{n=1}^{\mathrm{C} / \mathrm{A}}-\frac{\lambda}{2 \pi} \varphi_{n=1}^{\mathrm{C} / \mathrm{A}, \mathrm{NCO}}\right)$ assures $E_{n=1}^{\mathrm{NCO}}=0$. Similarly,

$E_{n} \equiv \rho_{n}^{\mathrm{C} / \mathrm{A}}-\frac{\lambda}{2 \pi}\left(\varphi_{n}^{\mathrm{C} / \mathrm{A}, \mathrm{NCO}}+\varphi_{n}^{\mathrm{C} / \mathrm{A}, \mathrm{res}}\right)+C$

with C/A residual carrier phase $\varphi_{n}^{\mathrm{C} / \mathrm{A} \text {,res }}$ and $C=-\left(\rho_{n=1}^{\mathrm{C} / \mathrm{A}}-\right.$ $\left.\frac{\lambda}{2 \pi}\left(\varphi_{n=1}^{\mathrm{C} / \mathrm{A}, \mathrm{NCO}}+\varphi_{n=1}^{\mathrm{C} / \mathrm{A}, \mathrm{res}}\right)\right)$ is shown in the right panel of Fig. 7. 

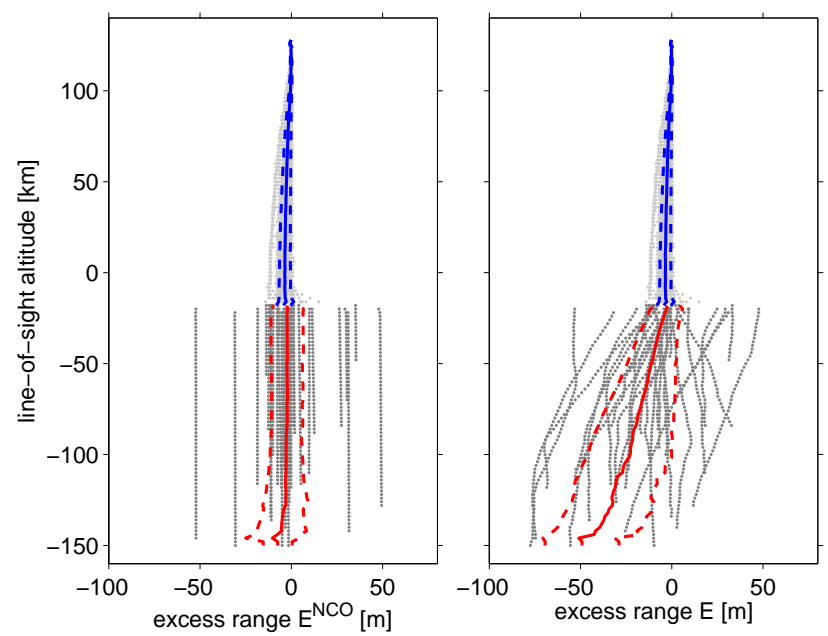

Fig. 7. Range deviation for 180 occultation events recorded on 7 August 2008. Left: excess range $E^{\mathrm{NCO}}$ as a function of lineof-sight altitude. Right: excess range $E$ as a function of line-ofsight altitude. The individual closed-loop (open-loop) data points are marked in light (dark) grey. Solid and dashed lines indicate the mean and standard deviations for the two subsets (OL in red, CL in blue). 4 events with deviations exceeding $100 \mathrm{~m}$ are excluded from the statistics. (For details see text.)

The constant values of the $E_{n}^{\mathrm{NCO}}$ profiles during OL tracking (Fig. 7, left panel) at LSA below about $-15 \mathrm{~km}$ confirms that the IGOR (TerraSAR-X) firmware uses the NCO carrier phase path to steer the code $\mathrm{NCO}$ as described by Ao et al. (2009) for the IGOR (COSMIC) and BlackJack (SAC-C) receiver firmware. We note, that occasionally discontinuities of several tens of meters occur, when IGOR switches from CL to OL tracking mode.

Without ionospheric dispersion the change in total (NCO plus residual) carrier phase path may serve as an approximation of the change in true atmospheric pseudorange. Thus, the observed deviations of $E_{n}$ from zero (Fig. 7, right panel) indicate an average mismodelling of the OL range model by about $50 \mathrm{~m}$ (1/6 of a C/A code chip length).

Obviously, the deviations between $f^{\mathrm{NCO}}$ and $f$ map from Doppler into refractivity space as well. I.e., if the residual phases $\varphi_{n}^{\text {res }}$ (Eq. 2) are disregarded and refractivities are reconstructed solely from the NCO phases, the corresponding refractivities, denoted by $N^{\mathrm{NCO}}$, differ from $N . N^{\mathrm{NCO}}$ is obtained analogous to $N$ except that the cut-off ray height is derived from the FSI amplitude belonging to $N$ (Jensen et al., 2003; Beyerle et al., 2006).

The resulting fractional refractivity errors with respect to ECMWF, $\Delta N^{\mathrm{NCO}} / N^{\mathrm{E}}$, are plotted in Fig. 8 (left panel) as black lines. The solid, dashed and dashed-dotted thick lines correspond to latitudes north of $30^{\circ} \mathrm{N}$, south of $30^{\circ} \mathrm{S}$ and latitudes between $30^{\circ} \mathrm{S}$ and $30^{\circ} \mathrm{N}$, respectively. For comparison, the fractional refractivity errors $\Delta N^{\mathrm{SD}} / N^{\mathrm{E}}$ (again ob-
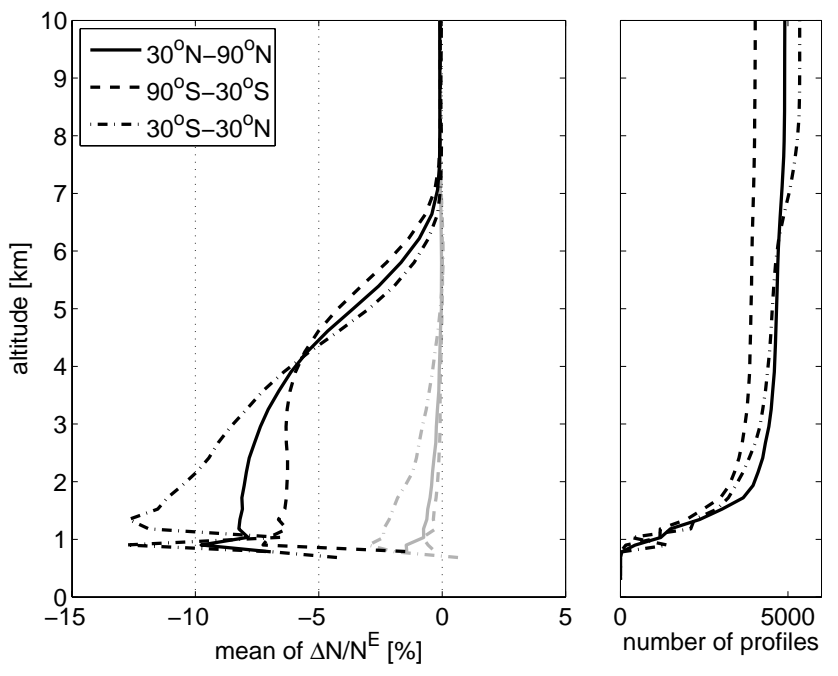

Fig. 8. Left: Fractional refractivity error derived solely from (single differencing) NCO phase data ignoring contributions from the residual phase samples (black lines). The results for the full measurement period (24 July and 17 November 2008) at three latitudinal bands are plotted as solid, dashed and dashed-dotted lines, respectively. For comparison the results obtained from the total (NCO plus residual) phase samples are shown as well (grey lines). Right: number of data points within the three latitudinal regions.

tained by single differencing, see discussion in Sect. 4.4) are plotted in grey. Below altitudes of about $7 \mathrm{~km} \Delta N^{\mathrm{NCO}} / N^{\mathrm{E}}$ exhibits a significant negative bias reaching a value of about $-12 \%$ at low latitudes.

In theory, the observed phase data samples $\varphi_{n}$ are independent of the chosen OL Doppler frequency model $f_{n}^{\mathrm{NCO}}$ (Sokolovskiy, 2001). I.e., a shift of $f_{n}^{\mathrm{NCO}}$ by an offset $\delta f$ will cause no change in $\varphi_{n}$, provided the deviation between $f_{n}^{\mathrm{NCO}}$ and the true atmospheric Doppler frequency remains below the Nyquist frequency (half of the sampling frequency) of $25 \mathrm{~Hz}$ (Sokolovskiy, 2001). This assumption implies that the observed refractivity values $N$ do not correlate with the $\mathrm{NCO}$ refractivity $N^{\mathrm{NCO}}$. We argue, however, that within the TerraSAR-X GPSRO data set the observed refractivities appear to exhibit a statistical dependency on $N^{\mathrm{NCO}}$ for C/A code SNRs below about $25 \mathrm{~V} / \mathrm{V}$. Specifically, the difference between $N$ and $N^{\mathrm{NCO}}$ is averaged over altitudes between 0 and $3 \mathrm{~km}$ (denoted as $\left\langle N-N^{\mathrm{NCO}}\right\rangle$ ) and plotted in Fig. 9 (top panel) as a function of minimum C/A code SNR value determined within this altitude range. The individual data points are sorted into SNR bins spaced by $10 \mathrm{~V} / \mathrm{V}$ and mean as well as standard deviations within each bin are determined. Individual data are plotted in grey, the mean and standard deviations are marked by red circles and vertical lines, respectively. For minimum SNRs between about $25 \mathrm{~V} / \mathrm{V}$ and $150 \mathrm{~V} / \mathrm{V}$ (at minimum SNRs larger than $150 \mathrm{~V} / \mathrm{V}$ the number of samples are too low to be significant, see Fig. 9, bottom panel) the mean value of $\left\langle N-N^{\mathrm{NCO}}\right\rangle$ remains at or below 

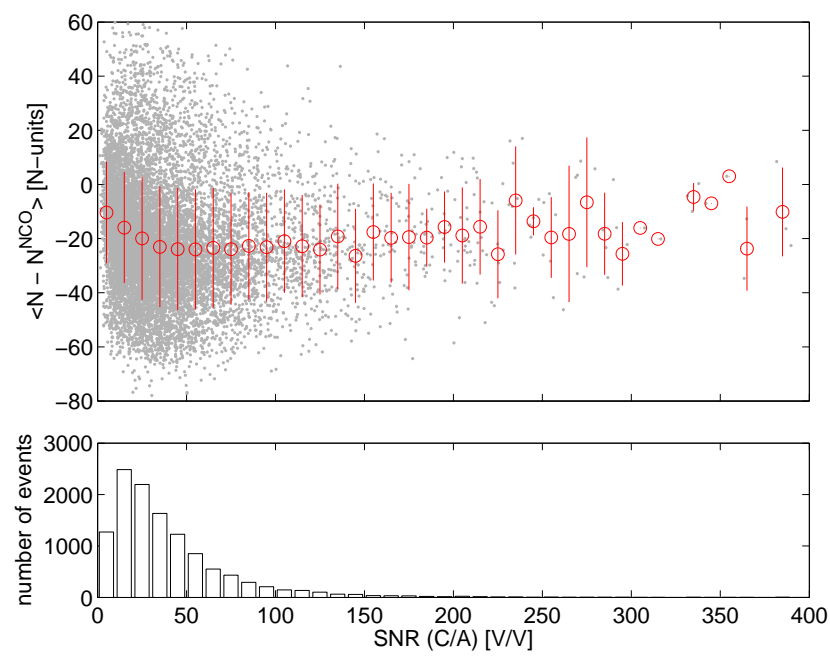

Fig. 9. Top: difference between the refractivities $N$ and $N^{\mathrm{NCO}}$, averaged between 0 and $3 \mathrm{~km}$ altitude, as a function of C/A code SNR (grey dots). Red circles mark the mean values in SNR bins spaced $10 \mathrm{~V} / \mathrm{V}$, vertical lines indicated the standard deviation. The analysis is based on the complete data set obtained during the time period 24 July to 17 November 2008. Bottom: number of occultation events within the individual SNR bins. (For details see text.)

$-20 N$-units. Below about $25 \mathrm{~V} / \mathrm{V}$, however, $N$ exhibits a tendency towards $N^{\mathrm{NCO}}$.

With the present OL data set we cannot provide a conclusive explanation for the observed behavior; more studies are needed to decide if this observation is relevant at all and, if it is, discuss possible solutions. As a first step forward we propose to modify the IGOR firmware and implement a second OL signal tracking channel. The carrier NCOs of the two OL channels will run at different Doppler frequencies, separated by, e.g., $25 \mathrm{~Hz}$. The output of both channels will be processed individually. Quality control procedures then compare the two derived carrier phase profiles and discard the observation if the two phase path profiles are found to deviate from each other.

\subsection{Validation with ECMWF analyses}

In this subsection the IGOR (TerraSAR-X) bending angle and refractivity profiles are compared with meteorological analysis results provided by the ECMWF. Pressure and temperature values at the time and location of the corresponding GPSRO measurement are calculated from the ECMWF fields using spatial and temporal linear interpolation between grid points $\left(0.5^{\circ} \times 0.5^{\circ}\right.$ horizontal resolution $)$ and analysis fields separated by $6 \mathrm{~h}$. The vertical resolution of the GPSRO refractivity profiles is $100 \mathrm{~m}$; the comparison between GPSRO observation and ECMWF data, however, is performed solely on the 91 ECMWF model levels ranging from the ground up to an altitude of about $80 \mathrm{~km}$ with a vertical resolution decreasing from about $25 \mathrm{~m}$ near the surface to about $500 \mathrm{~m}$ in the upper troposphere/lower stratosphere and to about $7 \mathrm{~km}$ at the upper model level. The comparison results, however, are not plotted as a function of the 91 ECMWF model level number, but as a function of the corresponding mean altitude.

In general, the bending angle profile $\alpha(p)$, corresponding a given refractivity profile $N$, follows from the inverse Abel transform (Fjeldbo et al., 1971; Hocke, 1997)

$\alpha(p)=-2 p \int_{p}^{\infty} \frac{d x}{\sqrt{x^{2}-p^{2}}} \frac{d \ln (n(x))}{d x}$.

Here, $n=1+10^{-6} N$ denotes the real part of the refractive index and $p$ is the impact parameter. Equation (9) is based on the assumption that the refractivity field is spherically symmetric, i.e. $N(\boldsymbol{r})=N(r)$.

The bending angle profile $\alpha^{\mathrm{E}}$ as a function of impact parameter $p$ corresponding to a given ECMWF refractivity profile $N^{\mathrm{E}}$ is derived in the following way. First, on each of the 91 model levels $N^{\mathrm{E}}$ is calculated from the corresponding ECMWF temperature, pressure and humidity data. Second, $N^{\mathrm{E}}(z)$ is upsampled on an equidistant altitude grid with $25 \mathrm{~m}$ step size using log-linear interpolation. Third, $N^{\mathrm{E}}(z)$ is extended from the upmost ECMWF altitude level (about $80 \mathrm{~km}$ ) up to $120 \mathrm{~km}$ using log-linear extrapolation. Finally, the high-resolution profile $\alpha^{\mathrm{E}}$ is derived using Eq. 9 and downsampled to the ECMWF impact parameter grid $p_{i}^{\mathrm{E}} \equiv n^{\mathrm{E}}\left(z_{i}\right) \cdot\left(z_{i}-h_{G}+r_{E}\right)$ by a log-linear fit of $\alpha^{\mathrm{E}}$ within each of the 91 impact parameter bins

$\left[p_{i}^{\mathrm{E}}-\delta p_{i}^{-}, p_{i}^{\mathrm{E}}+\delta p_{i}^{+}\right] \quad j=1, \ldots, 91$

and evaluation of the fit function at $p_{i}^{\mathrm{E}}$. Here, $r_{E}$ denotes Earth's local curvature radius, $h_{G}$ is the geoid height and

$\delta p_{i}^{+} \equiv \delta p_{i+1}^{-} \equiv\left(p_{i+1}^{\mathrm{E}}-p_{i}^{\mathrm{E}}\right) / 2$.

In addition, we set $\delta p_{1}^{-} \equiv \delta p_{1}^{+}$and $\delta p_{91}^{+} \equiv \delta p_{91}^{-}$.

The result of the comparison between 15327 IGOR (TerraSAR-X) GPSRO profiles and corresponding ECMWF data in terms of the fractional bending angle error as a function of ray height is shown in Fig. 10. The mean and standard deviation of $\Delta \alpha / \alpha^{\mathrm{E}}$, are plotted in the left and middle panel of Fig. 10 (black lines) for the three latitudinal bands $90^{\circ} \mathrm{S}$ to $30^{\circ} \mathrm{S}$ (4418 profiles), $30^{\circ} \mathrm{S}$ to $30^{\circ} \mathrm{N}$ (5705 profiles) and $30^{\circ} \mathrm{N}$ to $90^{\circ} \mathrm{N}$ (5204 profiles). In addition, in grey color the corresponding result using the non-optimized instead of the statistically optimized bending angles are plotted up to ray heights of $55 \mathrm{~km}$. Above $55 \mathrm{~km}$ the (non-optimized) results exhibit strong fluctuations exceeding $100 \%$. The right panel shows the averaged statistical optimization weight $w_{\text {SO }}$ corresponding to the three subsets. $w_{\text {SO }}$ gives the relative contribution of the observed to the statistically optimized bending angle $\alpha^{\mathrm{RO}}$ (Sokolovskiy and Hunt, 1996; Hocke, 1997; Healy, 2001; Wickert et al., 2004). E.g. $w_{\text {SO }}=0.7$ indicates that the a priori profile, derived from the MSIS climatology 


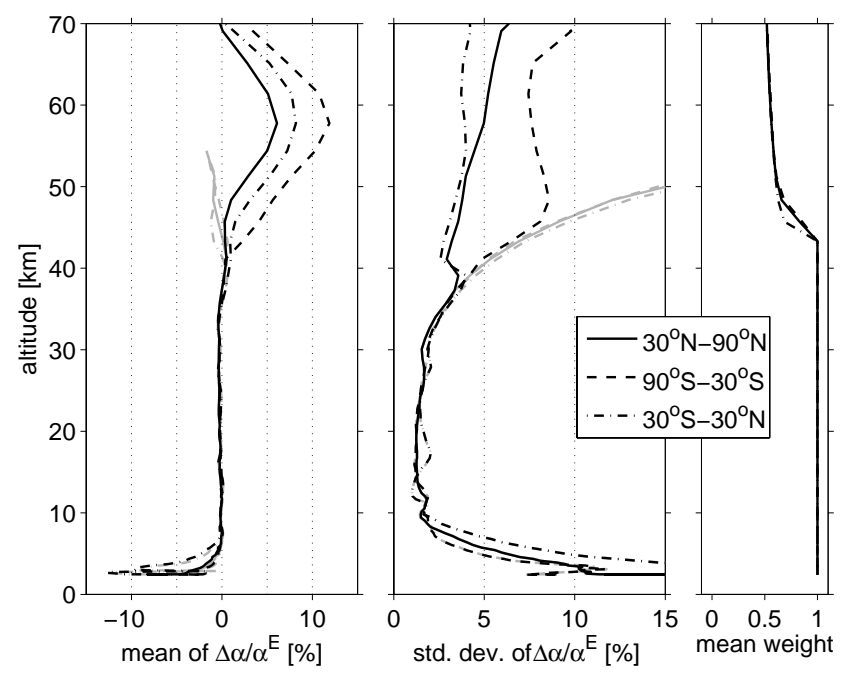

Fig. 10. Comparison of 15327 IGOR (TerraSAR-X) bending angle profiles with collocated ECMWF analysis results. The measurement period is 24 July to 17 November 2008. The result of statistically optimized bending angles using the MSIS climatology are plotted in black, grey lines mark the corresponding result for the non-optimized (raw) observation. The data is processed by GFZ's experimental processing system POCS-X using single differencing. Left: mean fractional bending angle error for three meridional zones, $90^{\circ} \mathrm{S}-30^{\circ} \mathrm{S}$ (dashed lines), $30^{\circ} \mathrm{S}-30^{\circ} \mathrm{N}$ (dashed-dotted), $30^{\circ} \mathrm{N}-90^{\circ} \mathrm{N}$ (solid). Center: standard deviation of fractional bending angle error. Right: mean value of the statistical optimization weight.

(Hedin, 1991), contributes $30 \%$ to $\alpha^{\mathrm{RO}}$ and the remaining $70 \%$ originate from the GPSRO observation.

The result of the comparison between 15327 IGOR (TerraSAR-X) GPSRO profiles and corresponding ECMWF data in terms of the fractional refractivity error as a function of altitude is shown in Fig. 11. The mean and standard deviation of $\Delta N / N^{\mathrm{E}}$, are plotted in the left and middle panel of Fig. 11 (black lines) for the three latitudinal bands. The right panel shows the number of refractivity observations as a function of altitude.

The biases of the mean fractional refractivity error at altitudes between 5 and $30 \mathrm{~km}$ varies between zero and $-0.30 \%$. Standard deviations decrease from about $1.4 \%$ at $5 \mathrm{~km}$ to about $0.6 \%$ at $10 \mathrm{~km}$ altitude, however, increase significantly in the upper stratosphere. The strong negative bias of the mean fractional refractivity error at low latitudes and altitudes below $5 \mathrm{~km}$ is well known from earlier GPSRO missions (Ao et al., 2003; Xie et al., 2010) and most likely related to critical refraction at and within the tropical boundary layer. Recently, Sokolovskiy et al. (2010) describe a significant correlation between the lowest line-of-sight altitude and the mean fractional refractivity error in the lower troposphere. By adjusting the cut-off height for each individual occultation event they succeed in reducing the tropospheric bias to less than $-1 \%$ for non-tropical and to about $-2 \%$
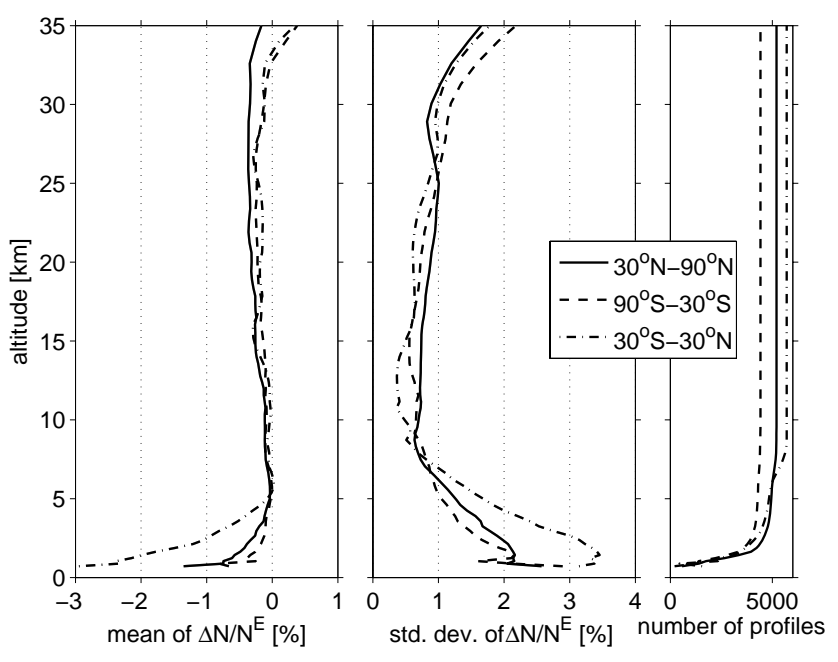

Fig. 11. Statistical comparison of 15327 IGOR (TerraSAR-X) refractivity profiles with collocated ECMWF analysis results. The observation period is 24 July to 17 November 2008; the data is processed by by GFZ's experimental processing system POCS-X using single differencing. Left: mean fractional refractivity error for three meridional zones, $90^{\circ} \mathrm{S}-30^{\circ} \mathrm{S}$ (dashed lines), $30^{\circ} \mathrm{S}-30^{\circ} \mathrm{N}$ (dashed-dotted), $30^{\circ} \mathrm{N}-90^{\circ} \mathrm{N}$ (solid). Center: standard deviation of the fractional refractivity error. Right: number of data points.

for tropical observations (Sokolovskiy et al., 2010). We note that these advanced methods for an optimal adjustment of retrieval parameters are not implemented in GFZ's GPSRO processing systems.

For comparison, the corresponding mean and standard deviation of the fractional refractivity error profiles from GRACE-A observations are plotted in Fig. 12 (Beyerle et al., 2005; Wickert et al., 2009). The data set, containing 15159 GPSRO observations, was collected during the same period as the TerraSAR-X measurements (24 July to 17 November 2008) and processed by GFZ's operational processing system POCS (Wickert et al., 2009).

The comparison of both, IGOR (TerraSAR-X) and BlackJack (GRACE-A) data with ECMWF refractivities (Figs. 11 and 12) exposes a small increase in standard deviation at the tropical tropopause (about 16-18 km altitude). Most likely these features are related to inadequate ECMWF modelling of small scale structures at the tropical tropopause level. The occurrence of enhanced standard deviations is most prominent at the tropical tropopause level, though; in both data sets standard deviations decrease by about a factor of two when comparing refractivities at the tropopause and about 4 to $6 \mathrm{~km}$ below that altitude.

Both, the IGOR (TerraSAR-X) as well as the GRACE-A results exhibit a negative refractivity bias of about -0.2 to $-0.3 \%$ in the upper troposphere and lower stratosphere. (left panels in Figs. 11 and 12). Whilst the observed refractivity bias might to some degree induced by ECMWF, we should 

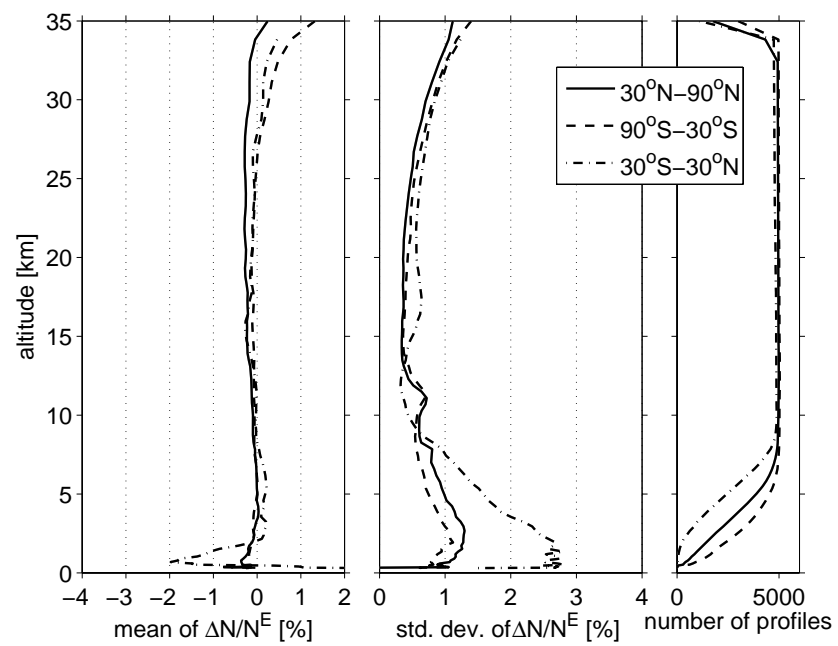

Fig. 12. Same as Fig. 11 but for 15159 GRACE-A GPSRO observations recorded during the same time period and processed by GFZ's operational processing system POCS.

also point out that $N^{\mathrm{RO}}$ is sensitive to the particular choice of filter parameters in a polynomial derivative filter which is used to smooth the excess Doppler profile. Assuming a tangent point vertical velocity of $2 \mathrm{~km} / \mathrm{s}$ a filter of degree three and order 101 translates into a cut-off wavelength $(-3 \mathrm{~dB}$ point) of about $3.33 \mathrm{~km}$ (see, e.g., Hamming, 1989; Beyerle and McDermid, 1999). In other words, the filter attenuates vertical wavelengths shorter that about $6.7 \mathrm{~km}$ by more than $50 \%$. Reduction of the filter degree from three to two and a change of the filter order from 101 to 41 yields a cut-off wavelength of about $2.86 \mathrm{~km}$. The corresponding refractivity error statistics are plotted in Fig. 13. The modified filter improves the average bias in the altitude region between 5 and $30 \mathrm{~km}$ by about a factor of two from $-0.17 \%$ to $-0.08 \%$.

The main difference between the IGOR and BlackJack results in the lower troposphere is due to OL signal tracking implemented in IGOR (TerraSAR-X) and modified closedloop ("fly-wheeling") tracking implemented in BlackJack (GRACE-A) (Ao et al., 2003; Beyerle et al., 2006). OL tracking significantly improves the data yield at altitudes below about $7 \mathrm{~km}$, as is evident from the comparison of the observation number profiles (right panels in Figs. 11 and 12). The improvement in tropospheric penetration gained by OL tracking is quantitatively described in terms of the $50 \%$-altitude $250 \%$, which we define as the altitude at which the normalized number of observations decreases to $50 \%$. Specifically, the IGOR (TerraSAR-X) data set yields $z 50 \%=$ $1.22 \mathrm{~km}, 1.35 \mathrm{~km}$ and $1.23 \mathrm{~km}$ for the three latitude regions $30^{\circ} \mathrm{N}$ to $90^{\circ} \mathrm{N}, 30^{\circ} \mathrm{S}$ to $30^{\circ} \mathrm{N}$ and $90^{\circ} \mathrm{S}$ to $30^{\circ} \mathrm{S}$. These depths are about 1.5 to $3.5 \mathrm{~km}$ lower than the corresponding $50 \%$-altitudes from the BlackJack (GRACE-A) data set, which are $z_{50 \%}=3.22 \mathrm{~km}, 5.00 \mathrm{~km}$ and $2.06 \mathrm{~km}$ for the same three latitudinal zones.
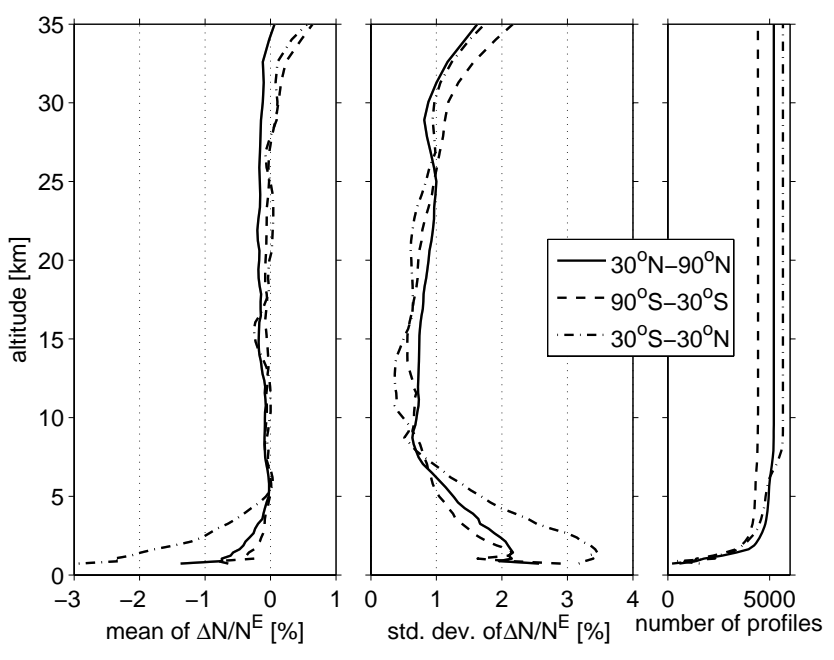

Fig. 13. Same as Fig. 11, but derivative filter parameters reduced from degree three to two and filter order reduced from 101 to 41 (for details see text).

\section{Conclusions}

Following the BlackJack occultation receivers aboard CHAMP and the GRACE-A/GRACE-B twin satellites, the IGOR instrument aboard TerraSAR-X constitutes another recent addition to current spaceborne GPSRO experiments. IGOR provides continuous GPSRO observations since July 2008. Since 21 October 2010 TerraSAR-X observations are included in GFZ's GPSRO operational processing system POCS and distributed via WMO's GTS (Global Telecommunications System) to international meteorological centers (e.g., ECMWF, UK Met Office, Meteo France, NCEP, JMA and DWD).

In the present study 15,327 refractivity profiles collected between 24 July and 17 November 2008 are analyzed by the experimental processing system POCS-X and compared with collocated ECMWF analysis data. In terms of refractivity deviations from collocated ECMWF profiles we find a mean bias between zero and $-0.30 \%$ within the altitude range between 5 and $30 \mathrm{~km}$. In contrast to the BlackJack receivers aboard CHAMP and GRACE-A/GRACE-B, IGOR aboard TerraSAR-X features open-loop tracking at low ray tangent point altitudes. Open-loop signal tracking significantly improves the data yield in the lower troposphere and reduces the $50 \%$-altitude on average by about $2.6 \mathrm{~km}$. Since a significant number of observations exceed Doppler frequency deviations of $20 \mathrm{~Hz}$ and reach the OL Nyquist frequency of $25 \mathrm{~Hz}$, an increase of the open-loop sampling rate from 50 to $100 \mathrm{~Hz}$ should be considered for future versions of the IGOR receiver firmware. 
Acknowledgements. We gratefully acknowledge the help and support by the TerraSAR-X teams at UT-CSR, GSOC/DLR and GFZ. The European Centre for Medium-Range Weather Forecasts provided meteorological analysis fields. GFZ's navigation data bit archive may be accessed through the Information System and Data Center at http://isdc.gfz-potsdam.de. We thank two anonymous reviewers for their thoughtful comments and suggestions.

Edited by: T. J. Dunkerton

\section{References}

Anthes, R. A., Bernhardt, P. A., Chen, Y., Cucurull, L., Dymond, K. F., Ector, D., Healy, S. B., Ho, S.-P., Hunt, D. C., Kuo, Y.-H., Liu, H., Manning, K., McCormick, C., Meehan, T. K., Randel, W. J., Rocken, C., Schreiner, W. S., Sokolovskiy, S. V., Syndergaard, S., Thompson, D. C., Trenberth, K. E., Wee, T.-K., Yen, N. L., and Zeng, Z.: The COSMIC/FORMOSAT-3 Mission: Early Results, B. Am. Meteorol. Soc., 89, 313-333, doi:10.1175/BAMS89-3-313, 2008.

Ao, C. O., Meehan, T. K., Hajj, G. A., Mannucci, A. J., and Beyerle, G.: Lower-Troposphere Refractivity Bias in GPS Occultation Retrievals, J. Geophys. Res., 108, 4577, doi:10.1029/2002JD003216, 2003.

Ao, C. O., Hajj, G. A., Meehan, T. K., Dong, D., Iijima, B. A., Mannucci, A. J., and Kursinski, E. R.: Rising and setting GPS occultations by use of open-loop tracking, J. Geophys. Res., 114, D04101, doi:10.1029/2008JD010483, 2009.

Arras, C., Wickert, J., Beyerle, G., Heise, S., Schmidt, T., and Jacobi, C.: A global climatology of ionospheric irregularities derived from GPS radio occultation, Geophys. Res. Lett., 35, L14809, doi:10.1029/2008GL034158, 2008.

Beyerle, G.: Carrier phase wind-up in GPS reflectometry, GPS Solutions, 13, 191-198, doi:10.1007/s10291-008-0112-1, 2009.

Beyerle, G. and McDermid, I. S.: Altitude range resolution of differential absorption lidar ozone profiles, Appl. Opt., 38, 924927, doi:10.1364/AO.38.000924, 1999.

Beyerle, G., Wickert, J., Schmidt, T., and Reigber, C.: GPS radio occultation with GRACE: Atmospheric profiling utilizing the zero difference technique, Geophys. Res. Lett., 32, L13806, doi:10.1029/2005GL023109, 2005.

Beyerle, G., Schmidt, T., Wickert, J., Heise, S., Rothacher, M., König-Langlo, G., and Lauritsen, K. B.: Observations and simulations of receiver-induced refractivity biases in GPS radio occultation, J. Geophys. Res., 111, D12101, doi:10.1029/2005JD006673, 2006.

Beyerle, G., Ramatschi, M., Galas, R., Schmidt, T., Wickert, J., and Rothacher, M.: A data archive of GPS navigation messages, GPS Solutions, 13, 35-41, doi:10.1007/s10291-008-0095-y, 2009.

Bonnedal, M., Christensen, J., Carlström, A., and Berg, A.: MetopGRAS in-orbit instrument performance, GPS Solutions, 14, 109120, doi:10.1007/s10291-009-0142-3, 2010.

Fjeldbo, G., Kliore, A. J., and Eshleman, V. R.: The neutral atmosphere of Venus as studied with the Mariner V radio occultation experiments, Astron. J., 76, 123-140, 1971.

Foelsche, U., Borsche, M., Steiner, A. K., Gobiet, A., Pirscher, B., Kirchengast, G., Wickert, J., and Schmidt, T.: Observing upper troposphere-lower stratosphere climate with radio occultation data from the CHAMP satellite, Clim. Dynam., 31, 49-65, doi:10.1007/s00382-007-0337-7, 2008.
Gorbunov, M. E. and Lauritsen, K. B.: Analysis of wave fields by Fourier integral operators and their application for radio occultations, Radio Sci., 39, RS4010, doi:10.1029/2003RS002971, 2004.

Gorbunov, M. E., Gurvich, A. S., and Bengtsson, L.: Advanced algorithms of inversion of GPS/MET satellite data and their application to reconstruction of temperature and humidity, Report 211, Max-Planck-Institut für Meteorologie, Hamburg, Germany, 1996.

Hajj, G. A. and Romans, L. J.: Ionospheric electron density profiles obtained with the Global Positioning System: Results from the GPS/MET experiment, Radio Sci., 33, 175-190, doi:10.1029/97RS03183, 1998.

Hajj, G. A., Kursinski, E. R., Romans, L. J., Bertiger, W. I., and Leroy, S. S.: A technical description of atmospheric sounding by GPS occultation, J. Atmos. Solar-Terr. Phys., 64, 451-469, 2002.

Hamming, R. W.: Digital filters, Prentice Hall, Englewood Cliffs, NJ, USA, 124-163, 1989.

Healy, S. B.: Smoothing radio occultation data bending angles above 40 km, Ann. Geophys., 19, 459-468, doi:10.5194/angeo19-459-2001, 2001.

Healy, S. B.: Forecast impact experiment with a constellation of GPS radio occultation receivers, Atmos. Sci. Lett., 9, 111-118, doi:10.1002/asl.169, 2008.

Hedin, A. E.: Extension of the MSIS thermosphere model into the middle and lower atmosphere, J. Geophys. Res., 96, 1159-1172, 1991.

Heise, S., Jakowski, N., Wehrenpfennig, A., Reigber, C., and Lühr, H.: Sounding of the topside ionosphere/plasmasphere based on GPS measurements from CHAMP: Initial results, Geophys. Res. Lett., 29, 1699, doi:10.1029/2002GL014738, 2002.

Heise, S., Wickert, J., Beyerle, G., Schmidt, T., and Reigber, C.: Global monitoring of tropospheric water vapor with GPS radio occultation aboard CHAMP, Adv. Space Res., 37, 2222-2227, doi:10.1016/j.asr.2005.06.066, 2006.

Hocke, K.: Inversion of GPS meteorology data, Ann. Geophys., 15, 443-450, doi:10.1007/s00585-997-0443-1, 1997.

Jensen, A. S., Lohmann, M. S., Benzon, H.-H., and Nielsen, A. S.: Full spectrum inversion of radio occultation signals, Radio Sci., 38, 1040, doi:10.1029/2002RS002763, 2003.

Jensen, A. S., Lohmann, M. S., Nielsen, A. S., and Benzon, H.-H.: Geometrical optics phase matching of radio occultation signals, Radio Sci., 39, RS3009, doi:10.1029/2003RS002899, 2004.

König, R., Michalak, G., Neumayer, K. H., Schmidt, R., Zhu, S. Y., Meixner, H., and Reigber, C.: Recent developments in CHAMP orbit determination at GFZ, in: Earth Observation with CHAMP, Results from Three Years in Orbit, Second CHAMP Science Meeting, Potsdam, 1-4 September 2003, edited by: Reigber, C., Lühr, H., Schwintzer, P., and Wickert, J., Springer, Berlin, 6570, doi:10.1007/3-540-26800-6_10, 2005.

Kuo, Y.-H., Sokolovskiy, S. V., Anthes, R. A., and Vandenberghe, F.: Assimilation of GPS Radio Occultation Data for Numerical Weather Prediction, Terrestrial, Atmos. Ocean. Sci., 11, 157186, 2000.

Kursinski, E. R., Hajj, G. A., Schofield, J. T., Linfield, R. P., and Hardy, K. R.: Observing Earth's atmosphere with radio occultation measurements using Global Positioning System, J. Geophys. Res., 19, 23429-23465, doi:10.1029/97JD01569, 1997.

Luntama, J.-P., Kirchengast, G., Borsche, M., Foelsche, U., Steiner, 
A., Healy, S., von Engeln, A., O'Clerigh, E., and Marquardt, C.: Prospects of the EPS GRAS Mission For Operational Atmospheric Applications, B. Am. Meteorol. Soc., 89, 1863-1875, doi:10.1175/2008BAMS2399.1, 2008.

Michalak, G. and König, R.: Rapid Science Orbits for CHAMP and GRACE Radio Occultation Data Analysis, in: System Earth via Geodetic-Geophysical Space Techniques, edited by Flechtner, F., Gruber, T., Güntner, A., Mandea, M., Rothacher, M., Schöne, T., and Wickert, J., Springer-Verlag, Berlin, Germany, 67-77, doi:10.1007/978-3-642-10228-8_6, 2010a.

Michalak, G. and König, R.: Near-Real Time Satellite Orbit Determination for GPS Radio Occultation with CHAMP and GRACE, in: System Earth via Geodetic-Geophysical Space Techniques, edited by: Flechtner, F., Gruber, T., Güntner, A., Mandea, M., Rothacher, M., Schöne, T., and Wickert, J., Springer-Verlag, Berlin, Germany, 443-454, doi:10.1007/978-3-642-10228-8_39, 2010b.

Misra, P. and Enge, P.: Global Positioning System: Signals, Measurements, and Performance, Ganga-Jamuna Press, Lincoln, MA 01773, USA, 317-363, 2006.

Perona, G., Notarpietro, R., and Gabella, M.: GPS radio occultation on-board the OCEANSAT-2 mission: An Indian (ISRO) - Italian (ASI) collaboration, Indian J. Radio Space Phys., 36, 386-393, 2007.

Pitz, W. and Miller, D.: The TerraSAR-X Satellite, IEEE Trans. Geosci. Remote Sens., 48, 615-622, doi:10.1109/TGRS.2009.2037432, 2010.

Randel, W. J., Wu, F., and Ríos, W. R.: Thermal variability of the tropical tropopause region derived from GPS/MET observations, J. Geophys. Res., 108, 4024, doi:10.1029/2002JD002595, 2003.

Rennie, M. P.: The impact of GPS radio occultation assimilation at the Met Office, Q. J. Roy. Meteorol. Soc., 136, 116-131, doi:10.1002/qj.521, 2010.

Ringer, M. A. and Healy, S. B.: Monitoring twenty-first century climate using GPS radio occultation bending angles, Geophys. Res. Lett., 35, L05708, doi:10.1029/2007GL032462, 2008.

Rocken, C., Anthes, R., Exner, M., Hunt, D., Sokolovskiy, S., Ware, R., Gorbunov, M., Schreiner, W., Feng, D., Herman, B., Kuo, Y.-H., and Zou, X.: Analysis and validation of GPS/MET data in the neutral atmosphere, J. Geophys. Res., 102, 29849-29866, doi:10.1029/97JD02400, 1997.

Rothacher, M., Tapley, B. D., Reigber, C., König, R., Falck, C., Grunwaldt, L., Köhler, W., Massmann, F.-H., and Michalak, G.: The tracking, occultation and ranging (TOR) instrument onboard TerraSAR-X and TanDEM-X, in: Proc. IEEE IGARSS, 23-28 July 2007, 4983-4986, 2007.

Schmidt, T., de la Torre, A., and Wickert, J.: Global gravity wave activity in the tropopause region from CHAMP radio occultation data, Geophys. Res. Lett., 35, L16807, doi:10.1029/2008GL034986, 2008.

Schmidt, T., Wickert, J., and Haser, A.: Variability of the upper troposphere and lower stratosphere observed with GPS radio occultation bending angles and temperatures, Adv. Space Res., 46, 150-161, doi:10.1016/j.asr.2010.01.021, 2010.

Schreiner, W., Rocken, C., Sokolovskiy, S., and Hunt, D.: Quality assessment of COSMIC/FORMOSAT-3 GPS radio occultation data derived from single- and double-difference atmospheric excess phase processing, GPS Solutions, 14, 13-22, doi:10.1007/s10291-009-0132-5, 2010.
Sokolovskiy, S. and Hunt, D.: Statistical optimization approach for GPS/MET data inversions, in: URSI GPS/MET workshop, Union Radio Sci. Int., 1996.

Sokolovskiy, S., Rocken, C., Hunt, D., Schreiner, W., Johnson, J., Masters, D., and Esterhuizen, S.: GPS profiling of the lower troposphere from space: Inversion and demodulation of the openloop radio occultation signals, Geophys. Res. Lett., 33, L14816, doi:10.1029/2006GL026112, 2006.

Sokolovskiy, S., Rocken, C., Schreiner, W., and Hunt, D.: On the uncertainty of radio occultation inversions in the lower troposphere, J. Geophys. Res., 115, D22111, doi:10.1029/2010JD014058, 2010.

Sokolovskiy, S. V.: Tracking tropospheric radio occultation signals from low Earth orbit, Radio Sci., 36, 483-498, doi:10.1029/1999RS002305, 2001.

Sokolovskiy, S. V., Rocken, C., Lenschow, D. H., Kuo, Y.-H., Anthes, R. A., Schreiner, W. S., and Hunt, D. C.: Observing the moist troposphere with radio occultation signals from COSMIC, Geophys. Res. Lett., 34, L18802, doi:10.1029/2007GL030458, 2007.

Sokolovskiy, S. V., Schreiner, W. S., Rocken, C., and Hunt, D. C.: Optimal noise filtering for the ionospheric correction of GPS radio occultation signals, J. Ocean. Atmos. Technol., 26, 13981403, doi:10.1175/2009JTECHA1192.1, 2009

Steiner, A. K., Kirchengast, G., Lackner, B. C., Pirscher, B., Borsche, M., and Foelsche, U.: Atmospheric temperature change detection with GPS radio occultation 1995 to 2008, Geophys. Res. Lett., 36, L18702, doi:10.1029/2009GL039777, 2009.

von Engeln, A., Healy, S., Marquardt, C., Andres, Y., and Sancho, F.: Validation of operational GRAS radio occultation data, Geophys. Res. Lett., 36, L17809, doi:10.1029/2009GL039968, 2009.

Werninghaus, R. and Buckreuss, S.: The TerraSAR-X Mission and System Design, IEEE Trans. Geosci. Remote Sens., 48, 606614, doi:10.1109/TGRS.2009.2031062, 2010.

Wickert, J., Beyerle, G., Hajj, G. A., Schwieger, V., and Reigber, C.: GPS radio occultation with CHAMP: Atmospheric profiling utilizing the space-based single difference technique, Geophys Res. Lett., 29, 1187, doi:10.1029/2001GL013982, 2002.

Wickert, J., Schmidt, T., Beyerle, G., König, R., Reigber, C., and Jakowski, N.: The radio occultation experiment aboard CHAMP: Operational data analysis and validation of atmospheric profiles, J. Meteorol. Soc. Jpn., 82, 381-395, 2004.

Wickert, J., Michalak, G., Schmidt, T., Beyerle, G., Cheng, C., Healy, S., Heise, S., Huang, C., Jakowski, N., Köhler, W., Mayer, C., Offiler, D., Ozawa, E., Pavelyev, A., Rothacher, M., Tapley, B., and Arras, C.: GPS radio occultation: Results from CHAMP, GRACE and FORMOSAT-3/COSMIC, Terrestrial, Atmos. Ocean. Sci., 20, 35-50, doi:10.3319/TAO.2007.12.26.01(F3C), 2009.

Wu, J. T., Wu, S. C., Hajj, G. A., Bertiger, W. I., and Lichten, S. M.: Effects of antenna orientation on GPS carrier phase, Manuscripta Geodaetica, 18, 91-98, 1993.

Xie, F., Wu, D. L., Ao, C. O., Kursinski, E. R., Mannucci, A. J., and Syndergaard, S.: Super-refraction effects on GPS radio occultation refractivity in marine boundary layers, Geophys. Res. Lett., 35, L11805, doi:10.1029/2010GL043299, 2010.

Yunck, T. P., Liu, C.-H., and Ware, R.: A history of GPS sounding, Terrestrial, Atmos. Ocean. Sci., 11, 1-20, 2000. 